\title{
SCHOLARLY INFLUENCE IN A DIVERSE LEGAL ACADEMY: RACE, SEX, AND CITATION COUNTS
}

\author{
DEBORAH JONES MERRITT*
}

\begin{abstract}
This article explores sex and race differences in scholarly influence by examining logged citation counts for all 815 professors who began tenure-track positions at accredited U.S. law schools between 1986 and 1991 and who remained on the tenure track in fall 1998. White men averaged significantly more citations than did women or minorities. The differences, however, were modest. Controlling for biographical variables through a series of regression equations, moreover, eliminated the citation gap between white men and both white and minority women, while substantially reducing the gap for minority men. The analyses suggest that most sex and race differences in citation counts are associated with differences in educational background, prestige of the institution at which a professor teaches, teaching assignments, and similar factors. As these differences diminish, already modest gaps in citation counts should decline as well.
\end{abstract}

$\mathrm{T}$

HE percentage of women law professors has almost tripled during the last 2 decades, while the proportion of minority faculty has quintupled.'

* John Deaver Drinko/Baker \& Hostetler Chair in Law, The Ohio State University, and Fellow, College of Law Center for Law, Policy, and Social Science. Jolie Havens and Adam Hall provided excellent assistance in gathering the citation counts for this study. Jennifer Cihon, George Hoskins, Rosanne Mitchell, Rachael Russo, and many other research assistants also contributed to building this database over the years. Kathryn Barry, James Brudney, Ruth Colker, Lowell Hargens, Timothy Jost, Andrew Merritt, Barbara Reskin, Allan Samansky, Barbara Snyder, and Gregory H. Williams all provided valuable suggestions on an earlier draft.

${ }^{1}$ In the fall of 1997 , the latest year for which statistics have been published, $1,540(28.5$ percent) of the 5,393 full-time professors in accredited law schools were women, while 719 (13.3 percent) of those professors were minorities. American Bar Association Section of Legal Education \& Admissions to the Bar, Official American Bar Association Guide to Approved Law Schools-1999 Edition 455 (1998). These figures include only tenured or tenure-track faculty who teach at least half time; the count excludes deans and others who administer more than half time. $I d$. at 61-62. In 1978, 429 (10.8 percent) of the 3,957 fulltime teachers on law faculties were women. American Bar Association Section of Legal Education \& Admissions to the Bar, A Review of Legal Education in the United States-Fall 1978 , at 62 (1979). At that time, unfortunately, the ABA did not report numbers of minority faculty members. The 1978 figures, moreover, include non-tenure-track faculty and probably overstate the percentage of women on the tenure track. On the basis of an independent survey of law school faculties, Richard Chused estimated that women constituted only 10.8 percent

[Journal of Legal Studies, vol. XXIX (January 2000)]

(C) 2000 by The University of Chicago. All rights reserved. 0047-2530/2000/2901-0015\$01.50 
Much of that growth occurred simply by opening doors previously closed to white women and people of color; some expansion derived from affirmative action programs designed to bring these excluded groups into the academy. ${ }^{2}$ How successful have these initiatives been? Have white women, women of color, and men of color established themselves as influential scholars in the legal academy? If these professors benefited from affirmative action, have they been able to keep up with their white male colleagues? If scholarly influence differs by race or sex, can we identify specific barriers to higher achievement?

This article begins to explore these questions by examining citation counts among professors who have held tenure-track positions at accredited law schools for the last 8-12 years. These professors began teaching between 1986 and 1991, when law schools proclaimed a strong commitment to affirmative action and hired a substantial number of female and minority scholars. By the fall of 1998 , the professors in this cohort were entering the most productive phase of their academic careers. ${ }^{3}$ Examining the citation counts of white men, white women, women of color, and men of color in this group of rising scholars provides an important measure of how well the latter three groups are establishing themselves in the academy. ${ }^{4}$

of tenured or tenure-track faculty by 1981 , while minorities composed 2.8 percent of those faculties in the same year. Richard H. Chused, The Hiring and Retention of Minorities and Women on American Law School Faculties, 137 U. Pa. L. Rev. 537, 540 n.19, 548 \& n.52 (1988).

${ }^{2}$ In a previous article, Barbara Reskin and I attempted to explore empirically the extent to which increased hiring of female and minority professors during the late 1980 s resulted from affirmative action preferences. That study suggests that preferences played a relatively small role in hiring, that women of color did not benefit from modest preferences extended to white women and men of color, and that sex bias (affecting both white women and women of color) continued to affect some aspects of hiring. See Deborah Jones Merritt \& Barbara F. Reskin, Sex, Race, and Credentials: The Truth about Affirmative Action in Law Faculty Hiring, 97 Colum. L. Rev. 199 (1997).

${ }^{3}$ See Theodore Eisenberg \& Martin T. Wells, Ranking and Explaining the Scholarly Impact of Law Schools, 27 J. Legal Stud. 373, 376 (1998) (noting that references to a law professor's work “peak at about 15-20 years into one's career”'); William M. Landes \& Richard A. Posner, Heavily Cited Articles in Law, 71 Chi.-Kent L. Rev. 825, 834 (1996) (on average, authors were 42.7 years old when they wrote articles later selected for a list of 100 most cited law review articles). Mean age for the professors in my population was 44.8 in the fall of 1998.

${ }^{4}$ Citation counts, of course, offer only one gauge of scholarly influence. It is possible to win many citations without exerting commensurate influence, and it is possible to wield considerable influence without gathering many citations. For this reason, citation counts are a poor measure for assessing the work of individual faculty members. When applied to a large population, however, citation counts offer a more trustworthy tool for measuring scholarly influence. Idiosyncracies that might affect an individual's citation rate-such as expertise in a field in which few others publish or an unusual name that is frequently miscited-will not affect comparisons of groups unless the idiosyncracy disproportionately affects one group. See William M. Landes \& Richard A. Posner, The Influence of Economics on Law: A Quantitative Study, 36 J. Law \& Econ. 385, 389 (1993). In addition, it is possible to control for some of these factors (such as differential citation rates in different subject matters) in multivariate group analyses. See text following note 34 infra. 
The analyses reported below show that female and minority scholars still lag somewhat behind white men in average citation counts. The differences, however, are small-especially when compared to other variations in citation rates, including those associated with subject matter specialties or religious background. For white women and women of color, moreover, the gap can be explained by factors such as parents' educational level, selectivity of the J.D. school, prestige of the tenure-track institution, and prehiring publications. The same variables explain much of the citation shortfall for men of color, although some differences remain between these men and their white male colleagues. A few women of color, finally, have been extraordinarily successful in generating citations: An African American woman tops the list of most cited scholars in this cohort, two other African American women join her in the top five, and a fourth African American woman rounds out the top 10 . The success of these individuals, together with the group analyses reported below, suggest that white women, women of color, and men of color have achieved a remarkable degree of scholarly influence within a single generation of joining the legal academy.

\section{Methods}

\section{A. Population}

The population includes all professors who began tenure-track positions at accredited law schools between the fall of 1986 and spring of 1991 and who remained on the tenure track in the fall of $1998 .^{5}$ Professors who moved from a tenure-track position at one accredited law school to a tenure-track post at another accredited school are included in the population. ${ }^{6}$ A total of 815 professors constitutes the population. ${ }^{7}$

\footnotetext{
5 As explained in previous studies drawing on the same database, "tenure-track professors" includes those with titles of assistant, associate, full, or (in California's public schools) acting professor who were neither librarians nor primarily clinical or skills teachers. See Merritt \& Reskin, supra note 2, at 209-10.

6 By the fall of 1998 , almost one-fifth (18.4 percent) of the population had moved permanently from one school to another. Minority professors were significantly more likely to move than their white colleagues $(p=.002)$. Almost one-third (30.0 percent) of minority men changed institutions, while 26.3 percent of minority women did so. In contrast, only 16.9 percent of white men and 15.9 percent of white women moved from one school to another. Professors who changed institutions averaged significantly more citations (154.1) than those who remained at one school $(81.9, p=.000)$. The same relationship persisted when I logged citations (see note 27 and accompanying text infra) and compared means for the two groups (4.43 for professors who moved; 3.79 for those who did not; $p=.000$ ). I did not include a variable for relocation in my regression analyses because I am concerned here primarily with factors that antecede citation counts. Relocation is as likely to stem from scholarly influence as to precede it.

${ }^{7}$ Between 1986 and 1991, 1,086 professors started tenure-track positions; the attrition rate was 25.0 percent. See text around note 54 infra for discussion of issues related to attrition.
} 
By the fall of 1998 , more than two-thirds (69.0 percent) of these faculty members had attained the rank of full professor, while another tenth $(9.8$ percent) held named professorships or chairs. More than three-quarters of the population, therefore, had achieved the highest professorial ranks. Another fifth (20.2 percent) of the population held the rank of associate professor, while just eight faculty members (1.0 percent) remained assistant professors. Given their length of time in teaching and the professorial ranks they held, the overwhelming majority of these professors must have been tenured by the fall of $1998 .{ }^{8}$

\section{B. Dependent Variable}

I measured citation counts using a method developed by Theodore Eisenberg and Martin Wells. ' Research assistants searched Westlaw's TP-ALL database for references to each population member using the formula "first name w/2 last name." For professors using more than one middle name, they expanded the search to "first name w/3 last name." 10 My assistants examined the first 10 "hits" for each professor; if all were positive they recorded the total number of hits as the professor's citation count. If any of the first 10 was a false hit, and the professor had fewer than 30 citations, they examined all hits. For professors with more than 29 citations, my assistants examined the first 20 hits and estimated the total number of citations from the percentage of correct hits in that batch of $20 .{ }^{11}$ All citation counts occurred between mid-November 1998 and mid-January 1999. ${ }^{12}$

${ }^{8}$ Most law schools, like other academic departments, require professors either to achieve tenure by the end of the sixth year or to depart after a seventh, terminal year at the institution. All of the professors in this population entered the tenure track 8-12 years before 1998. A few may have interrupted their teaching careers or secured tenure rollbacks, but the overwhelming majority-especially among the associate and full professors-must have been tenured.

${ }^{9}$ Eisenberg \& Wells, supra note 3.

${ }^{10} I d$. at $379-80,383$. See id. at $377-86$ for further discussion of the TP-ALL database and basic method.

"This sampling method tracks Eisenberg and Wells's technique, although I decided to examine the first 10 hits for every professor in the population to eliminate arbitrary decisions about what names are common. I eliminated overcounting of treatises authored by population members, a problem identified by Eisenberg and Wells, by comparing citation counts in TPALL with counts for the same professor in JLR (a Westlaw database that includes journals but not treatises). I then examined citation lists for professors registering a substantial discrepancy to determine whether the additional hits in TP-ALL were citations in treatises (which I counted) or multiple sections of works the professor had authored (which I eliminated except for the initial hit). Compare Eisenberg \& Wells, supra note 3, at 380-81.

${ }^{12} 1$ did not use the time adjustments employed by Eisenberg and Wells because my assistants completed all counts within the space of 2 months. Compare Eisenberg \& Wells, supra note 3, at 384-85. Small discrepancies in citation counts due to elapsed time, moreover, are unlikely to affect my analyses because the order in which my assistants processed professors (a modified alphabetical list) did not correlate with any of the variables of interest. Eisenberg 
I refined the Eisenberg and Wells method in three ways. First, from previous work with the same population of professors, I had compiled a list of professors who had changed their last name. For these professors, my assistants searched for "first name w/2 (last namel or last name2)." They followed a similar approach for professors whose middle name could have been a family name and for those with hyphenated last names. ${ }^{13}$ We employed these variations for both male and female professors so that we could count citations accurately for any professor who changed his or her name through marriage or divorce.

Second, again building on previous work with these faculty members, my research assistants could refer to lists of books and articles published by each professor. For faculty members with common last names, they were thus able to make educated decisions about positive and negative hits in the database.

Finally, if an initial query yielded no hits, my assistants examined the publication lists to formulate an alternative query. In one case, for example, the publication list revealed that a professor published exclusively under his middle and last names; a reformulated search identified a substantial number of cites. To reduce repetitive searches, we pursued this approach only when the initial search yielded no hits. For other professors, we assumed that undercounting was randomly distributed among population members. ${ }^{14}$

\section{Independent Variables}

I identified each professor's sex and race from the AALS Directory of Law Professors, a survey mailed to population members in 1991, and information provided by the AALS executive office. The number of minority professors, unfortunately, was too small to support separate analyses of each minority race. Therefore, as in previous studies, I grouped professors into four categories: white men, white women, men of color, and women of color. ${ }^{15}$

and Wells, in contrast, apparently processed professors by school-and were particularly interested in average citation counts for each school. Time adjustments, therefore, were essential for them.

${ }^{13}$ For professors with hyphenated last names, my assistants searched for the full hyphenated name as well as for both halves of the name.

${ }^{14}$ I checked citation counts for the top 50 population members identified by my assistants, as well as for several dozen randomly selected members of the population. Within both groups, my assistants were quite accurate.

${ }^{15}$ See, for example, Merritt \& Reskin, supra note 2; Deborah Jones Merritt, Research and Teaching on Law Faculties: An Empirical Exploration, 73 Chi.-Kent L. Rev. 765 (1998). In these previous studies, I created one variable reflecting minority status, a second denoting sex, and an interaction term between those two variables. In the analyses discussed below, I use dummy variables to identify white women, women of color, and men of color, with white men as the reference category for all three. The techniques produce identical results, but the 
From the AALS Directory and other published sources, I gathered information about the prestige of each professor's undergraduate school; prestige of his or her J.D. school; law review membership and editorial positions; possession of a master's degree in law; possession of a master's degree or doctoral degree in a field other than law; experience as a judicial clerk for a state supreme court, federal district court, federal court of appeals, or the U.S. Supreme Court; and experience in private practice. ${ }^{16} \mathrm{I}$ also determined the year of the professor's first tenure-track law school appointment, age at the time of that appointment, ${ }^{17}$ prestige of the school at which the appointment occurred, ${ }^{18}$ and whether the professor was inbred (hired by the same school from which he or she obtained a J.D.). ${ }^{19} \mathrm{I}$ also counted the number of different courses the professor listed in the 1996-97 AALS Directory (course diversity), the number of different seminars listed in that directory (seminar diversity), and whether any of those courses or seminars fell in the fields of constitutional law, corporate law, family law, taxation, trusts and estates, or skills. ${ }^{20}$

From a survey mailed to population members during the fall of $1997,{ }^{21} \mathrm{I}$

dummy variables are somewhat easier to follow in discussion. Of the 127 minority faculty in this population, 80 (63.0 percent) were African American, 25 (19.7 percent) were Latino/ Latina, 12 (9.4 percent) were Asian American, 6 (4.7 percent) were Native American, and 4 (3.1 percent) self-identified as minorities, but their race or ethnicity could not be determined.

${ }^{16}$ For further description of these prehiring variables, see Merritt \& Reskin, supra note 2, at 222-23. As explained there, Barbara Reskin and I developed a scale combining median LSAT and academic reputation rank (both as reported by U.S. News \& World Report) to measure law school prestige. $I d$. at 212-13. In previous studies, I analyzed 10 different types of law practice. For the current analyses, I found a bivariate distinction between professors with private practice experience (in law firms, with corporations, or as solo practitioners) and all other professors most meaningful.

${ }^{17}$ In preliminary analyses, I also included the rank at which each professor joined the tenure track. Inspection revealed that initial rank correlated highly with age at time of appointment $(r=.486)$ and that rank never improved the explanatory power of a regression equation, while age sometimes did. I thus included age, but not rank, in the analyses reported here.

18 Although about one-fifth of the professors moved from one institution to another (see note 6 supra), I used prestige of the initial tenure-track institution in all analyses reported here. Substituting prestige of the 1998 institution did not materially affect coefficients for the variables discussed below, but it reduced slightly the full equation's explanatory power. Future work will explore more fully the relationship between citation counts and mobility; here, I am concerned primarily with biographical antecedents that may predict high citation counts.

${ }^{19}$ Once again, these variables are described in greater detail in Merritt \& Reskin, supra note 2, at 211-16, 223-24. "Inbred" professors include only those who obtained their first tenure-track post at their J.D. school; professors who returned to that J.D. school through a lateral hire do not count as inbred in this study.

${ }^{20}$ For more detail, see Merritt, supra note 15 , at 778 . For these analyses, I combined courses on legal writing, legal research, clinical subjects, trial advocacy, and appellate advocacy into a single skills category.

${ }^{21}$ For further information on all of the variables drawn from the survey, see Merritt, supra note 15 , at $772-80$. For professors still on the tenure track in fall 1998, the survey produced a healthy response rate of 57.3 percent. To guard against possible bias in voluntary survey 
determined the number of credit hours taught by each faculty member, the number of semesters of research leave the professor obtained between 1992 and 1997, whether the professor had ever won a teaching award, the religion in which the professor was raised, ${ }^{22}$ the average educational level attained by the professor's parents, and whether the professor characterized his or her political views as "moderately" or "strongly" conservative. ${ }^{23}$

A final set of variables measures each professor's scholarly output both before and after entering the tenure track. Using several electronic databases, I counted the number of scholarly articles each professor published in a top-20 law journal both before and after hiring, the number of scholarly articles published in other journals during both periods, and the number of books published before and after joining the tenure track. ${ }^{24}$ Article counts are current as of June 1996, while book counts end in summer 1997. ${ }^{25}$

Tables 1 and 2 summarize information about each of the independent

responses, I used a variable denoting survey response in my multivariate analyses. See also $i d$. at $772-73$. An earlier survey of the same population generated information about family status and job search strategies. In preliminary analyses, variables drawn from this survey did not produce significant coefficients in any of the regression analyses discussed here; I thus dropped these variables. The failure of these variables to show any significant association with citation counts does not mean that family status bears no relationship to those counts. My information on family status was a decade or more out-of-date. More current information might show such a relationship.

${ }^{22}$ This survey question focused on religious background, rather than current religious belief, asking respondents "In what religion were you raised?' I created three dummy variables to denote professors who characterized their religious background as Catholic, Jewish, or "no religion." Protestant professors constituted the reference group in multivariate analyses. Four professors identified their background as Muslim or Buddhist; I coded these professors as missing on all three religious dummies because of their very small representation in the population.

${ }^{23}$ I constructed this variable from a survey question asking professors whether they would characterize their "political perspective" as (1) strongly liberal or left; (2) moderately liberal; (3) middle-of-the-road; (4) moderately conservative; or (5) strongly conservative or right. Preliminary analyses revealed that three-quarters of the population (75.4 percent) chose one of the first two responses, while another seventh (14.5 percent) characterized themselves as middle-of-the-road. The tenth of respondents (10.2 percent) choosing one of the two conservative replies appeared to form a distinct minority, so I created a dummy variable combining the two conservative categories.

${ }^{24}$ For further description of these variables, see Merritt, supra note 15, at 769-72, 776. "Scholarly articles" include articles and essays published in both law reviews and scholarly journals from other disciplines. I excluded book reviews, dedications, and works published in newspapers, bar journals, or other nonscholarly fora. For the "top 20"' law journals, I used the list of 20 most cited law reviews compiled by James Lindgren and Daniel Seltzer. James Lindgren \& Daniel Seltzer, The Most Prolific Law Professors and Faculties, 71 Chi.-Kent L. Rev. 781, 791 (1996). Book counts combine all types of works, including treatises, casebooks, practitioner works, and university press books.

${ }^{25}$ The need to gather large amounts of data for the population prompted these staggered ending dates - both of which precede my citation counts by 18 months or more. The gap between publication and citation counts, however, parallels the time needed for a work to gather published citations. 
TABLE 1

MEANS For IndePendent Variables, by SEX/Race Group

\begin{tabular}{|c|c|c|c|c|c|}
\hline Variable & $\begin{array}{l}\text { White } \\
\text { Men }\end{array}$ & $\begin{array}{l}\text { White } \\
\text { Women }\end{array}$ & $\begin{array}{l}\text { Men of } \\
\text { Color }\end{array}$ & $\begin{array}{l}\text { Women of } \\
\text { Color }\end{array}$ & $\begin{array}{c}\text { All } \\
\text { Faculty }\end{array}$ \\
\hline College selectivity & $\begin{array}{l}64.49 \\
(8.57)\end{array}$ & $\begin{array}{l}63.87 \\
(8.69)\end{array}$ & $\begin{array}{c}62.39 \\
(11.40)\end{array}$ & $\begin{array}{c}62.55 \\
(10.85)\end{array}$ & $\begin{array}{l}64.01 \\
(9.04)\end{array}$ \\
\hline J.D. school prestige & $\begin{array}{c}2.70 \\
(1.57)\end{array}$ & $\begin{array}{c}2.26 \\
(1.66)\end{array}$ & $\begin{array}{c}2.28 \\
(2.02)\end{array}$ & $\begin{array}{c}2.82 \\
(1.48)\end{array}$ & $\begin{array}{c}2.55 \\
(1.65)\end{array}$ \\
\hline Year of tenure-track job & $\begin{array}{l}88.07 \\
(1.44)\end{array}$ & $\begin{array}{l}88.22 \\
(1.41)\end{array}$ & $\begin{array}{l}88.63 \\
(1.19)\end{array}$ & $\begin{array}{l}88.33 \\
(1.48)\end{array}$ & $\begin{array}{l}88.18 \\
(1.42)\end{array}$ \\
\hline Tenure-track institution prestige & $\begin{array}{c}.22 \\
(2.01)\end{array}$ & $\begin{array}{c}.10 \\
(1.82)\end{array}$ & $\begin{array}{c}.43 \\
(2.09)\end{array}$ & $\begin{array}{l}-.45 \\
(1.91)\end{array}$ & $\begin{array}{c}.16 \\
(1.96)\end{array}$ \\
\hline Course diversity & $\begin{array}{c}3.99 \\
(1.46)\end{array}$ & $\begin{array}{c}3.61 \\
(1.27)\end{array}$ & $\begin{array}{c}3.62 \\
(1.38)\end{array}$ & $\begin{array}{c}3.46 \\
(1.14)\end{array}$ & $\begin{array}{c}3.81 \\
(1.39)\end{array}$ \\
\hline Seminar diversity & $\begin{array}{c}.67 \\
(.82)\end{array}$ & $\begin{array}{c}.94 \\
(1.06)\end{array}$ & $\begin{array}{c}.75 \\
(.95)\end{array}$ & $\begin{array}{c}.72 \\
(.98)\end{array}$ & $\begin{array}{c}.76 \\
(.92)\end{array}$ \\
\hline Teaching load & $\begin{array}{l}11.89 \\
(2.25)\end{array}$ & $\begin{array}{l}11.57 \\
(2.05)\end{array}$ & $\begin{array}{l}10.89 \\
(1.95)\end{array}$ & $\begin{array}{l}11.57 \\
(1.22)\end{array}$ & $\begin{array}{l}11.70 \\
(2.12)\end{array}$ \\
\hline Research leaves & $\begin{array}{c}.63 \\
(.71)\end{array}$ & $\begin{array}{c}.77 \\
(.76)\end{array}$ & $\begin{array}{c}.32 \\
(.55)\end{array}$ & $\begin{array}{c}.61 \\
(.89)\end{array}$ & $\begin{array}{c}.66 \\
(.74)\end{array}$ \\
\hline Prehire top-20 articles & $\begin{array}{c}.32 \\
(.65)\end{array}$ & $\begin{array}{l}.12 \\
(.37)\end{array}$ & $\begin{array}{l}.10 \\
(.52)\end{array}$ & $\begin{array}{l}.00 \\
(.34)\end{array}$ & $\begin{array}{l}.22 \\
(.83)\end{array}$ \\
\hline Other prehire articles & $\begin{array}{l}1.26 \\
(2.28)\end{array}$ & $\begin{array}{c}.81 \\
(1.39)\end{array}$ & $\begin{array}{c}.74 \\
(1.50)\end{array}$ & $\begin{array}{l}.23 \\
(.60)\end{array}$ & $\begin{array}{c}1.02 \\
(1.93)\end{array}$ \\
\hline Prehire books & $\begin{array}{l}.19 \\
(.52)\end{array}$ & $\begin{array}{l}.09 \\
(.35)\end{array}$ & $\begin{array}{l}.13 \\
(.51)\end{array}$ & $\begin{array}{l}.00 \\
(.19)\end{array}$ & $\begin{array}{c}.14 \\
(.46)\end{array}$ \\
\hline Posthire top-20 articles & $\begin{array}{l}1.12 \\
(2.13)\end{array}$ & $\begin{array}{c}.72 \\
(1.28)\end{array}$ & $\begin{array}{c}.79 \\
(1.84)\end{array}$ & $\begin{array}{c}.42 \\
(1.13)\end{array}$ & $\begin{array}{c}.92 \\
(1.84)\end{array}$ \\
\hline Other posthire articles & $\begin{array}{c}4.77 \\
(4.43)\end{array}$ & $\begin{array}{c}3.38 \\
(2.77)\end{array}$ & $\begin{array}{c}3.77 \\
(2.69)\end{array}$ & $\begin{array}{c}2.89 \\
(2.25)\end{array}$ & $\begin{array}{c}4.15 \\
(3.81)\end{array}$ \\
\hline Posthire books & $\begin{array}{c}.82 \\
(1.56)\end{array}$ & $\begin{array}{c}.47 \\
(.98)\end{array}$ & $\begin{array}{c}.43 \\
(.84)\end{array}$ & $\begin{array}{c}.32 \\
(.60)\end{array}$ & $\begin{array}{c}.65 \\
(1.32)\end{array}$ \\
\hline Parents' education & $\begin{array}{c}3.97 \\
(.78)\end{array}$ & $\begin{array}{l}3.93 \\
(.78)\end{array}$ & $\begin{array}{c}3.62 \\
(1.01)\end{array}$ & $\begin{array}{l}3.69 \\
(.93)\end{array}$ & $\begin{array}{l}3.92 \\
(.81)\end{array}$ \\
\hline Age at tenure-track appointment & $\begin{array}{l}34.97 \\
(5.75)\end{array}$ & $\begin{array}{c}35.04 \\
(4.80)\end{array}$ & $\begin{array}{l}35.10 \\
(5.44)\end{array}$ & $\begin{array}{l}34.36 \\
(5.44)\end{array}$ & $\begin{array}{l}34.95 \\
(5.42)\end{array}$ \\
\hline$N$ & 449 & 239 & 70 & 57 & 815 \\
\hline
\end{tabular}

NoTE.-Standard deviations are in parentheses.

variables for the population as a whole, as well as for each of the four sex/ race groups I analyze.

\section{Results}

Of the 815 law professors who entered the tenure track between 1986 and 1991, and who remain on that track today, 449 (55.1 percent) are white men, 239 (29.3 percent) are white women, 70 (8.6 percent) are men of color, and 57 ( 7.0 percent) are women of color. Citation counts for all four 
TABLE 2

Percentages Registering Positive for Dummy Variables, by Sex/Race Group

\begin{tabular}{lrrrrr}
\hline \hline & $\begin{array}{c}\text { White } \\
\text { Men }\end{array}$ & $\begin{array}{c}\text { White } \\
\text { Women }\end{array}$ & $\begin{array}{c}\text { Men of } \\
\text { Color }\end{array}$ & $\begin{array}{c}\text { Women of } \\
\text { Color }\end{array}$ & $\begin{array}{c}\text { All } \\
\text { Faculty }\end{array}$ \\
\hline Mariable & 20.4 & 19.2 & 5.7 & 8.8 & 18.0 \\
Main law review staff & 31.4 & 30.0 & 17.1 & 8.8 & 28.4 \\
Secondary law review staff & 3.4 & 3.8 & 5.7 & 7.0 & 3.9 \\
Secondary law review editor & 7.4 & 6.7 & 7.1 & 8.8 & 7.4 \\
LL.M. & 12.1 & 16.7 & 14.3 & 15.8 & 13.9 \\
M.A. & 29.8 & 23.8 & 28.6 & 24.6 & 27.7 \\
Ph.D. & 15.2 & 7.1 & 5.7 & .0 & 10.9 \\
State court clerk & 5.9 & 5.5 & 4.3 & 7.0 & 5.7 \\
District court clerk & 8.1 & 13.4 & 7.2 & 15.8 & 10.2 \\
Court of appeals clerk & 26.2 & 23.9 & 13.0 & 12.3 & 23.4 \\
Supreme Court clerk & 6.3 & 4.6 & 4.3 & .0 & 5.2 \\
Private practice & 74.7 & 71.1 & 64.7 & 68.4 & 72.4 \\
Inbred & 8.3 & 11.1 & 16.2 & 1.8 & 9.3 \\
Constitutional law & 23.4 & 14.2 & 21.7 & 14.0 & 19.9 \\
Corporate law & 18.3 & 10.5 & 18.8 & 14.0 & 15.7 \\
Family law & 3.1 & 20.1 & 2.9 & 8.8 & 8.5 \\
Skills & 18.0 & 29.3 & 13.0 & 22.8 & 21.2 \\
Tax law & 8.0 & 8.4 & 4.3 & 5.3 & 7.6 \\
Trusts and estates & 4.0 & 7.1 & .0 & 8.8 & 4.9 \\
Teaching award & 40.7 & 32.5 & 39.3 & 18.8 & 36.2 \\
Conservative & 14.1 & 6.3 & 3.7 & 3.4 & 9.9 \\
Catholic & 28.7 & 24.4 & 28.6 & 31.3 & 27.3 \\
Jewish & 26.1 & 23.1 & .0 & .0 & 21.6 \\
Protestant & 40.9 & 47.5 & 60.7 & 53.1 & 45.3 \\
No religion & 3.9 & 4.4 & 7.4 & 12.9 & 4.9 \\
Returned survey & 53.7 & 69.5 & 40.0 & 56.1 & 57.2 \\
$N$ & 449 & 239 & 70 & 57 & 815 \\
\hline
\end{tabular}

NoTE. $-N$ for variables reflecting conservative political views, religion, and teaching awards is limited to between 443 and 467 survey respondents who answered those questions.

groups are impressive. White men averaged 107.9 citations; women of color, 90.7; white women, 78.8; and men of color, 73.1.6 ${ }^{26}$ The most cited professor had accumulated 995 citations by the end of 1998 . The top 5 percent (41 professors) all had achieved more than 317 citations.

A histogram of citation counts (Figure 1) shows that the citation counts are strongly skewed to the right. Eight population members, in particular, attracted an exceptional number of cites. Ninety-nine percent of the population accumulated 522 or fewer citations; the eight remaining professors

${ }^{26}$ Medians for all four groups lagged behind means, reflecting the impact of faculty with extraordinarily high citation counts in all four groups. The median count for white men was 64.0; for white women it was 48.0; for men of color, 39.5; and for women of color, 29.0. The gap between mean and median was particularly large for women of color, reflecting the very high citation rates of four women in that group. See text preceding note 48 infra. 


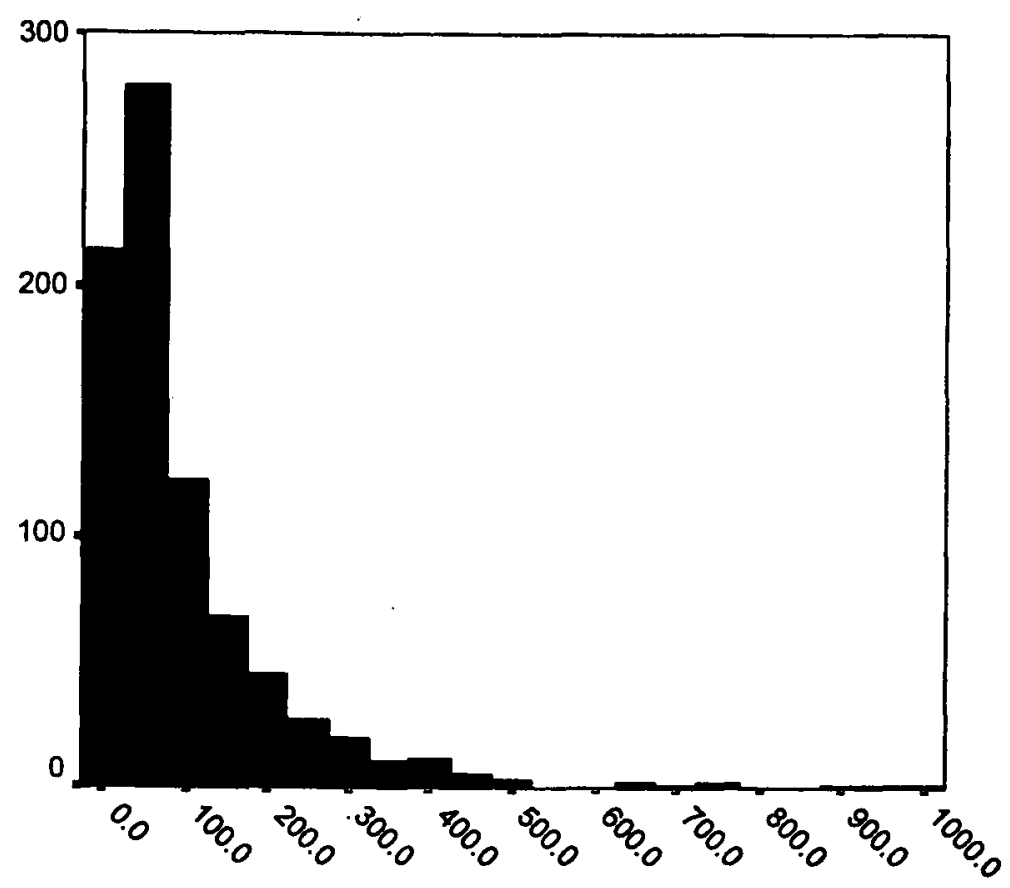

\section{Number of Citations (as of December 1998)}

FIGURE 1.-Citation counts for 815 law professors who began teaching between 1986 and $1991 ; N=815$, mean $=95.2, \mathrm{SD}=117.35$.

each achieved 628 or more cites. The demographic composition of the eight "superstars" is also unusual: three of these professors (including the most cited professor and three of the top five) are women of color, one is a white woman, and four are white men. Women of color thus are greatly overrepresented ( 37.5 percent) among the most cited professors, while both white women and men of color are underrepresented. White men appear in a slightly smaller proportion (50.0 percent) than they appear in the full population.

To correct for the skew in citation counts, as well as to model more accurately nonlinear relationships between some independent variables and citations, I use the natural log of citations for the remaining analyses in this section. ${ }^{27} \mathrm{~A}$ one-way analysis of variance, with logged citation counts as the

${ }^{27}$ For the 10 population members with zero citations, I defined the natural log of citations as -.69 . This created the same gap in natural log value between professors with zero and one citation as between those with one and two citations. Using a different value $(-1.0$ or 0 ) for professors with no citations had no meaningful effect on the analyses reported here. 
TABLE 3

ORdinary Least SQuares Regressions for Natural Log of Citation Counts, Equations (1)-(3)

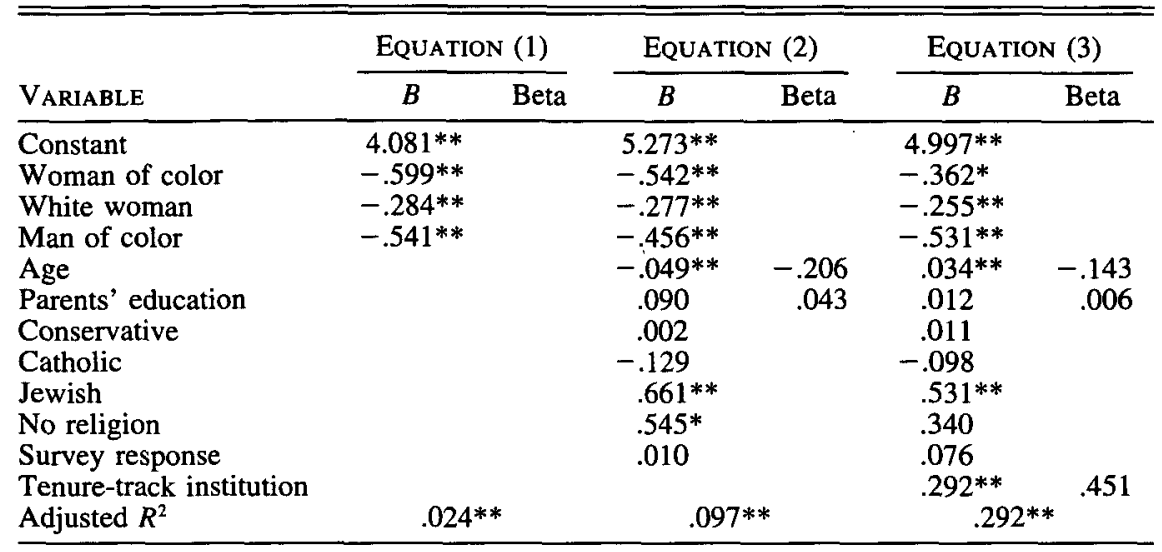

Note. $-N=815 . B=$ nonstandardized coefficients, Beta $=$ standardized coefficients. Standardized coefficients are not reported for dummy variables. Full results for all three equations, including standard errors and $p$-levels, are available from me.

${ }^{*} p \leq .05$.

$* * p \leq .01$.

dependent variable, revealed significant differences among the four sex/ race groups, $F(3,811)=7.68, p=.000$. The mean of logged citation counts for white men (4.08) was significantly higher than that for white women $(3.80, p=.004)$, men of color $(3.54, p=.001)$, and women of color $(3.48, p=.001)$. Means for the latter three groups did not differ significantly from one another, although the difference between white women and women of color approached significance $(p=.086)$.

To probe these race and sex differences, I created a series of seven regression equations using logged citation counts as the dependent variable. By adding sets of independent variables in stages, I explore the extent of sex- and race-related differences in citation rates, as well as possible origins of those differences. The first five equations exclude measures of productivity among the independent variables. These equations thus examine the relationship of sex, race, and other independent variables to a dependent variable (logged citation counts) that includes dimensions of both productivity and per-publication impact. The final two equations assess the relationship between the independent variables and logged citation counts with productivity controlled. Equations (6) and (7) thus explore the citation "payoff" that professors obtain when productivity and other factors are constant.

Equation (1) (Table 3) includes only the three dummy variables denoting white women, women of color, and men of color; white men constitute the 
reference category. Coefficients for all three variables are negative and significant. These sex- and race-related variables, however, explain only 2.4 percent of the variance in logged citation counts, underscoring the relatively small differences among the four sex/race groups in scholarly influence. The percentage of variance attributable to sex and race differences never exceeded this amount, no matter what other variables were in the equation. ${ }^{28}$

Equation (2) (Table 3) adds six variables reflecting other personal characteristics that, like sex and race, do not express personal achievement but might show some association with scholarly influence: age, parents' educational level (a proxy for socioeconomic background), self-identification as a conservative, and three dummies denoting religious background. ${ }^{29}$ Professors from Protestant families form the reference group for the religion variables.

This equation explains almost 10 percent of the variance in logged citation counts. The coefficients for age and Jewish background, which point in opposite directions, are both significant. At least before controlling for educational and professional background, a greater age at time of tenuretrack appointment is associated with fewer citations, while a Jewish upbringing predicts a higher number of citations. A nonreligious background is also associated with more citations, but this effect is smaller than that for Jewish background.$^{30}$ Neither parents' educational level nor self-identification as a conservative shows a significant association with logged citation counts. $^{31}$

The coefficients for white women, women of color, and men of color all remain significant and negative in equation (2). The coefficients for both men and women of color, however, are noticeably smaller than in equation

${ }^{28}$ I tested adding the three sex/race variables to the equation after each set of variables used in equations (2)-(7). When added after the variables in equation (2), the sex/race variables explained 1.8 percent of the variance in citation counts; when added after the variables in equations (2) and (3), they explained 1.6 percent of the variance; after equations (2)-(4), 1.1 percent; after equations (2)-(5), 0.9 percent; and after equations (2)-(6), 0.3 percent. When added after all of the other variables reflected in equations (2)-(7), these sex/race variables accounted for only the final 0.4 percent of variance in citation counts.

${ }^{29}$ A seventh variable controls for survey response, a measure of missing values for surveygenerated data. The coefficient for survey response lacks significance in all regressions, suggesting that missing values from nonrespondents did not bias the analyses.

${ }^{30}$ The coefficient for Catholic professors is not significant, which indicates that citation counts for these professors do not differ significantly from those of their Protestant peers. In an alternative equation using Jewish professors as the reference group, coefficients for both Catholic and Protestant professors were negative and significant. Jewish professors thus differ significantly from both Catholic and Protestant professors in generating citations, but the latter two groups do not differ from one another.

${ }^{31}$ Parents' educational level does correlate with citation counts $(r=.131, p=.005)$ before controlling for race and religion. Conservative views, however, show no correlation with citation counts before $(r=-.012, p=.802)$ or after controlling for other variables. 
(1). The decline stems from controlling for Jewish background and parents' educational level, both variables with a positive association with citation counts $^{32}$ but a negative correlation with minority status. No professor of color in the population had a Jewish background, and parents' educational level for professors of color (3.66) was significantly lower than for white professors (3.96, $p=.008)$. Part of the race differences in equation (1), in other words, can be attributed to differences in religious or socioeconomic background. ${ }^{33}$

Equation (3) (Table 3) adds a single variable, prestige of the institution at which each professor began tenure-track teaching. With inclusion of this variable, the variance explained by the equation jumps to 29.2 percent. Controlling for prestige of the tenure-track institution noticeably reduces the size of coefficients for white women, women of color, age, Jewish background, and nonreligious background, although all but the last of these remain significant. These changes reflect the fact that white women, women of color, and older professors (all variables with negative coefficients) teach, on average, at less prestigious institutions than other faculty, while professors from Jewish or nonreligious backgrounds (both variables with positive coefficients) teach, on average, at more prestigious institutions. Controlling for prestige of the tenure-track institution thus diminishes the size of these coefficients. The negative coefficient for men of color, conversely, rises after controlling for institutional prestige, which reflects the fact that men of color teach, on average, at more prestigious institutions than their white male counterparts. ${ }^{34}$

Equation (4) (Table 4) adds 13 other variables reflecting aspects of each professor's tenure-track position: year of appointment, credit hours taught, diversity of courses and seminars, research leaves, teaching awards, inbred status, and dummy variables for six different teaching subjects. Course diversity, seminar diversity, and teaching constitutional law show a signifi-

${ }^{32}$ Although the coefficient for parents' educational level is not significant in equation (2), that variable did show a significant, positive association with citation counts when added by itself to equation (1). Controlling for age reduced the explanatory power of parents' educational level.

${ }^{33}$ None of these variables necessarily cause differences in citation counts; race, religion, and socioeconomic background-like other variables in the succeeding equations--merely predict those differences. The comparison between equations (1) and (2), however, shows that one can explain some of the variation in citation counts by focusing on religious or socioeconomic categories as well as racial ones.

${ }^{34}$ For comparisons among white women, women of color, men of color, and white men, see Table 1. Professors from Protestant families taught at institutions with an average prestige rating of -.08 ; the average rating for professors from nonreligious families was .70 , and that for Jewish professors was .48. The Protestant/Jewish difference was significant $(p=.021)$, while the Protestant/no-religion difference approached significance $(p=.068)$. The correlation coefficient between age and prestige of tenure-track institution was $-.142(p=.000)$. 
TABLE 4

Ordinary LEast SQUares Regressions for Natural Log of Citation Counts, Equations (4)-(6)

\begin{tabular}{|c|c|c|c|c|c|c|}
\hline \multirow[b]{2}{*}{ VARIABLE } & \multicolumn{2}{|c|}{ EQUATION (4) } & \multicolumn{2}{|c|}{ EQUATION (5) } & \multicolumn{2}{|c|}{ EQUATION (6) } \\
\hline & $B$ & Beta & $B$ & Beta & $B$ & Beta \\
\hline Constant & $10.746 * *$ & & $9.803^{* *}$ & & $10.972 * *$ & \\
\hline Woman of color & $-.316^{*}$ & & $-.350^{*}$ & & -.175 & \\
\hline White woman & $-.153^{+}$ & & -.137 & & -.016 & \\
\hline Man of color & $-.503^{* *}$ & & $-.479 * *$ & & $-.336 * *$ & \\
\hline Age & $-.022 * *$ & -.095 & $-.018 * *$ & -.075 & $-.020 * *$ & -.086 \\
\hline Jewish & $.425 * *$ & & $.369 * *$ & & $.320 * *$ & \\
\hline Tenure-track institution & $.280^{* *}$ & .433 & $.233 * *$ & .360 & $.198 * *$ & .306 \\
\hline Tenure-track year & $-.065^{* *}$ & -.073 & $-.063 * *$ & -.071 & $-.079^{* *}$ & -.088 \\
\hline Credit hours & $-.046 *$ & -.057 & $-.045^{+}$ & -.057 & $-.047^{*}$ & -.058 \\
\hline Course diversity & $.076 * *$ & .083 & $.068^{*}$ & .074 & $.076 * *$ & .083 \\
\hline Seminar diversity & $.087^{*}$ & .063 & $.066^{+}$ & .048 & $.066^{+}$ & .048 \\
\hline Constitutional law & $.421 * *$ & & $.361 * *$ & & $.339 * *$ & \\
\hline Corporate law & -.125 & & -.097 & & -.089 & \\
\hline Family law & .027 & & .007 & & .010 & \\
\hline Tax law & $-.665 * *$ & & $-.757 * *$ & & $-.691 * *$ & \\
\hline Trusts and estates & $-.393 *$ & & $-.408^{*}$ & & $-.402 *$ & \\
\hline Skills courses & $-.345 * *$ & & $-.356 * *$ & & $-.334 * *$ & \\
\hline Inbred & $-.622 * *$ & & $-.423 * *$ & & $-.374 * *$ & \\
\hline Research leaves & .037 & .016 & .069 & .030 & .043 & .019 \\
\hline Teaching award & .024 & & .016 & & .046 & \\
\hline College selectivity & & & .007 & .046 & .006 & .043 \\
\hline J.D. prestige & & & $.093 * *$ & .120 & $.100 * *$ & .128 \\
\hline Secondary law review editor & & & $.256^{+}$ & & .186 & \\
\hline LL.M. & & & $.390 * *$ & & $.332 * *$ & \\
\hline Supreme Court clerk & & & $.414^{*}$ & & $.462 * *$ & \\
\hline Private practice & & & $-.160^{+}$ & & -.084 & \\
\hline Prehire top articles & & & & & $.327 * *$ & .144 \\
\hline Other prehire articles & & & & & $.088^{* *}$ & .134 \\
\hline Prehire books & & & & & $.154^{*}$ & .056 \\
\hline Adjusted $R^{2}$ & .390 & & .417 & & .457 & \\
\hline
\end{tabular}

Note. $-N=815 . B=$ nonstandardized coefficients, Beta = standardized coefficients. Standardized coefficients are not reported for dummy variables. For convenience, this table omits variables that failed to reach or approach significance in equations (1)-(3). Full results for all equations, including standard errors and $p$-levels, are available from me.

${ }^{+} p \leq .10$ (approaches significance).

$* p \leq .05$.

$* * p \leq .01$.

cant positive association with citation counts, while year of tenure-track appointment, credit hours, teaching tax, teaching trusts and estates, teaching skills courses, and being inbred all show significant negative associations.

The coefficients for men of color, women of color, and (most noticeably) white women are smaller in this equation than in the last one. For men of color, the reduction stems primarily from the controls for tenure-track year 
and inbred status. Men of color in this population started teaching significantly later than white men and they were significantly more likely to teach at the school where they obtained their J.D. ${ }^{35}$ For women of color and white women, the coefficient reduction derives from the controls for course diversity and teaching constitutional law, both conditions that are associated with higher citations counts but that women tend to lack. ${ }^{36}$ White women also suffered in citation counts from their heavy involvement in teaching skills courses, a curricular area that corresponds with fewer citations. After controlling for this and other factors in equation (4), the negative coefficient for white women merely approaches significance.

Equation (5) (Table 4) adds six variables associated with prehiring credentials: college selectivity, prestige of the J.D. school, experience as an editor for a secondary law review, possession of an LL.M., experience as a clerk for the United States Supreme Court, and experience in private practice. ${ }^{37}$ The first five of these variables show a positive association with citation counts, although only three are significant at the conventional .05 level. The final coefficient for private practice is negative and narrowly misses statistical significance.

Controlling for these prehiring credentials further diminishes the coefficient for white women; indeed, that coefficient does not even approach significance in this equation. As Table 1 reflects, the white women in this population attended significantly less prestigious J.D. schools than did white men $(p=.001)$. Controlling for this variable, which shows a strong positive association with citation counts, thus has a major impact on the coefficient for white women.

Taken as a whole, equation (5) illuminates the role of sex and race in predicting citation counts after controlling for personal characteristics, educational credentials, and professional attainments, but before controlling for productivity. After controlling for the factors in equation (5), white women matched white men on citation counts; white men and white women at similarly ranked institutions and with comparable backgrounds averaged the same number of citations.

The coefficients for men of color and women of color are still negative

${ }^{35}$ See Tables 1 and 2. For year of tenure-track appointment, $p=.002$; for inbred status, $p=.045$.

${ }^{36}$ As Table 1 shows, white women, men of color, and women of color all taught fewer different courses, on average, than did white men. All three of these differences are statistically significant $(p=.001, .041, .006)$. White women and women of color were also significantly less likely than white men and men of color to teach constitutional law $(p=.002)$.

${ }^{37}$ I tested variables for all of the other educational and professional experiences described in Section I, but none reached or even approached significance after controlling for factors already in the equation. For simplicity, I limited equation (5) to the variables listed in text. 
and significant in equation (5), but they are relatively small. Coefficients for eight other dummy variables (Jewish background, teaching constitutional law, teaching tax, teaching trusts and estates, teaching skills courses, inbred status, possession of an LL.M., and experience as a Supreme Court clerk) are all larger than the coefficient for being a woman of color; the coefficient for teaching tax is larger than that for being a man of color. Prestige of both the J.D. school and tenure-track institution also assume a substantial role in this equation. Compared with these other variables, race differences play a minor role in predicting variance in citation counts. ${ }^{38}$

Equation (6) (Table 4) adds three variables reflecting prehiring publications: the number of scholarly articles published in top-20 law journals before joining the tenure track, the number of scholarly articles published in other journals during that time, and the number of books published during the same period. Coefficients for all three of these variables are positive and significant: prehiring publications of all types predict higher citation counts after joining the tenure track. This is not surprising: those publications generate citations of their own and may also predict later success in scholarship.

Controlling for prehiring publications markedly affects the coefficients for white women, women of color, and men of color. Any potential difference between white women and white men diminishes to the point of triviality. The negative coefficient for minority women is substantially smaller, failing even to approach significance. The negative coefficient for minority men remains significant, but it too is considerably smaller. Differences in prehiring publications play a substantial role in explaining later citation gaps between white men and women of color, men of color, or white women. ${ }^{39}$

Equation (7) (Table 5), finally, adds variables counting the number of books, scholarly articles in top-20 law journals, and scholarly articles in other journals that each professor published after joining the tenure track. After including these variables, the regression equation explains 56.6 percent of the variance in logged citation counts. All three variables reflecting posthiring publications are positive and significant. As one would expect, both the number of posthiring articles published in top-20 journals and the

${ }^{38}$ If the three variables reflecting sex and race are added to the equation after all of the variables in equations (2)-(5), the sex and race dummies explain only 0.9 percent of the variance in citation counts.

${ }^{39}$ Table 1 shows the average publication rates for each sex/race group. For each prehiring productivity measure, the means for white men differ significantly from those for both white women and women of color. White men published significantly more scholarly articles and articles in top-20 law journals before joining a law school faculty than did men of color, but the two groups do not differ significantly in the amount of prehiring book publication. 
TABLE 5

ORDINARY LEAST SQUARES REgRESSION FOR NATURAL Log of Citation Counts, Equation (7)

\begin{tabular}{lccrrr}
\hline \hline Variable & $B$ & S.E. & Beta & \multicolumn{1}{c}{$t$} & Significance \\
\hline Constant & 3.172 & 2.032 & & 1.561 & .119 \\
Woman of color & -.057 & .125 & & -.454 & .650 \\
White woman & .080 & .075 & & 1.065 & .287 \\
Man of color & $-.287^{*}$ & .112 & & -2.555 & .011 \\
Age & -.010 & .006 & -.040 & -1.561 & .119 \\
Jewish & $.266^{*}$ & .110 & & 2.419 & .016 \\
Tenure-track institution & $.146^{* *}$ & .021 & .225 & 7.072 & .000 \\
Tenure-track year & -.001 & .022 & -.001 & -.032 & .975 \\
Credit hours & -.030 & .019 & -.037 & -1.533 & .126 \\
Course diversity & $.050^{*}$ & .024 & .054 & 2.071 & .039 \\
Seminar diversity & .040 & .034 & .029 & 1.167 & .243 \\
Constitutional law & $.245^{* *}$ & .079 & & 3.108 & .002 \\
Corporate law & $-.157^{+}$ & .087 & & -1.807 & .071 \\
Tax law & $-.585^{* *}$ & .122 & & -4.799 & .000 \\
Trusts and estates & $-.377^{* *}$ & .145 & & -2.598 & .010 \\
Skills courses & $-.237^{* *}$ & .079 & & -2.988 & .003 \\
Inbred & $-.327^{* *}$ & .121 & & -2.704 & .007 \\
College selectivity & $.007^{+}$ & .004 & .051 & 1.948 & .052 \\
J.D. prestige & $.083^{* *}$ & .025 & .107 & 3.336 & .001 \\
LL.M. & $.338^{* *}$ & .093 & & 3.612 & .000 \\
Prehire top articles & $.161^{* *}$ & .060 & .071 & 2.685 & .007 \\
Other prehire articles & .026 & .017 & .039 & 1.496 & .135 \\
Prehire books & $.146^{*}$ & .071 & .053 & 2.054 & .040 \\
Posthire top articles & $.202^{* *}$ & .020 & .294 & 10.090 & .000 \\
Other posthire articles & $.079^{* *}$ & .009 & .236 & 8.489 & .000 \\
Posthire books & $.059^{*}$ & .025 & .062 & 2.394 & .017 \\
Adjusted $R^{2}$ & $.566^{* *}$ & .836 & & & .000 \\
\hline
\end{tabular}

NoTE. $-N=815 . B=$ standardized coefficients, Beta $=$ standardized coefficients. Standardized coefficients are not reported for dummy variables. For convenience, several variables that failed to reach or approach significance have been omitted. Full results for those variables are available from me.

${ }^{+} p \leq .10$ (approaches significance).

$* p \leq .05$.

$*^{*} p \leq .01$.

number of articles published in other journals play a particularly strong role in predicting citation counts.

The coefficients for white women and women of color are both indistinguishable from zero in this equation. After controlling for productivity and all other variables in the equation, therefore, white women and women of color reap as many citations as their white male counterparts. The citation payoff for these women, in other words, seems to be the same as that for white men with similar levels of productivity and other credentials.

The coefficient for men of color in equation (7) again is smaller than in the previous equation, suggesting that some of the difference between men 
of color and white men stems from differences in posthiring productivity. The coefficient, however, remains both negative and significant, signaling the troubling possibility that men of color obtain a smaller citation payoff for each of their publications than do white men.

Several other relationships in equation (7) are noteworthy. Prestige of the tenure-track institution remains a powerful predictor of citation counts. ${ }^{40}$ Teaching constitutional law, tax, trusts and estates, or skills courses relates significantly to citation counts-even after controlling for differences in productivity among professors teaching these subjects. ${ }^{41}$ The coefficient for teaching corporate law also approaches significance in this equation, although it failed to do so in previous equations. It appears that professors of corporate law obtain lower citation payoffs for their work than do other professors, but compensate for that disadvantage by publishing more articles in top journals. ${ }^{42}$

The coefficients for both Jewish professors and those hired by their J.D. institution, finally, remain significant in this equation. Even after controlling for productivity, prestige of the tenure-track institution, and other factors, professors from Jewish families averaged more citations than their Protestant peers. Conversely, after controlling for other factors, professors who remained at their J.D. institution reaped fewer citations on average than faculty members who taught at an institution other than their J.D. school. The coefficient for the latter variable, moreover, is considerably larger than the coefficient for men of color, while the coefficient for Jewish background is similar in size to the one for men of color. Even when race remains a factor in predicting citation counts, it is one of many complex strands-and far from the most important.

${ }^{40}$ Many other scholars have noted the connection between prestigious teaching posts and high citations. For a humorous account, making the point as effectively as any empirical study, see J. M. Balkin \& Sanford Levinson, How to Win Cites and Influence People, 71 Chi.-Kent L. Rev. 843 (1996).

${ }^{41}$ The remaining associations probably reflect, at least in part, disparities in the number of articles offering citation opportunities within each field. Equation (7) controls for each author's productivity, but not for the overall number of articles published in each field. If law reviews publish 100 articles a year about federalism, but only two articles about the rule against perpetuities, an article on the former subject can generate many more citations than one on the latter. Articles about constitutional law may also be more susceptible than articles on other subjects to citation across fields; professors writing about corporate disclosure, consumer law, copyright, and lawyer advertising may all cite First Amendment theories. See also Fred R. Shapiro, The Most-Cited Law Review Articles Revisited, 71 Chi.-Kent L. Rev. 751, 762 (1996) ("A constitutional law article will have countless opportunities to pick up law review citations, but the most brilliant' article on wills would have so few opportunities that it could never qualify for a most-cited list').

${ }^{42}$ Corporte law professors published, on average, 1.46 articles in top-20 law journals after joining the tenure track, while other professors averaged just .83 articles in those journals $(p$ $=.000$ ) 


\section{Discussion}

White women, women of color, and men of color joined law school faculties in substantial numbers only during the last generation. With the weight of cultural history against them, stereotypes still in play, conflicting demands from home, and less traditional credentials than some of their white male counterparts, it would not be surprising if these academic newcomers had difficulty establishing strong scholarly reputations. Instead, the analyses in this paper suggest an impressive level of scholarly success for the white women, women of color, and men of color who joined law faculties during the late 1980s. Average citation counts for these professors lag somewhat behind counts for their white male peers, but four factors counsel optimism about the gap.

First, the gap is smaller than some observers have feared. White men averaged 108 citations after 8-12 years of teaching, but women of color averaged 91 citations during the same time period, white women averaged 79 , and men of color averaged 73 . In regression analyses, variables reflecting sex and race never explained more than 2.4 percent of the variance in logged citation counts. After controlling for all factors other than productivity, sex and race explained only 0.9 percent of that variance; after adding productivity to the equation, sex and race explained a minute 0.4 percent of the variance in citation counts. ${ }^{43}$

Second, sex and race differences in citation counts are particularly small when compared with other variations in academic citation rates. Jewish professors in this population averaged 143 citations, while Protestant faculty averaged just 85 . Professors who taught constitutional law averaged 136 citations, while those teaching tax averaged 42 and professors of trusts and estates averaged just 36 . Professors with a college-educated parent obtained an average of 101 citations, while faculty whose parents held no college degrees (almost one-quarter of the population) averaged only 67 citations. Our social focus on sex and race differences, prompted by long histories of discrimination on those grounds and recent attempts to remedy those biases, tends to magnify differences falling along sex and race divides while obscuring larger discrepancies in other categories.

Third, for both white women and women of color, the citation gap can be traced to factors such as socioeconomic background, religion, prestige of tenure-track institution, subjects taught, educational background, and number of prehiring publications. Once these variables are controlled for, white women and women of color generate as many citations, on average, as white men. They also reap the same citation payoff as white men do for

${ }^{43}$ See note 28 supra. 
books and articles published after joining the tenure track; controlling for posthiring productivity does not unmask any differences between white men and either white women or women of color.

Even for men of color, differences in religious background, parents' educational level, number of prehiring publications, posthiring productivity, and other factors explain a substantial portion of the citation gap. The negative coefficient for men of color dropped from a high of .541 in equation (1) to a low of .287 in equation (7). It is troubling that this coefficient remains significant even after controlling for all variables in the equation. In particular, the negative coefficient in equation (7) suggests that men of color-like professors of tax, trusts and estates, and possibly corporate law-average fewer citations than other professors for each work they publish. Still, the decline in magnitude of this coefficient, combined with the relatively small size of the remaining race effect, suggests that much of the difference between white men and men of color is attributable to factors such as prehiring productivity.

The power of these factors to explain most of the sex and race differences in citation counts is important, because sex and race differences in these explanatory variables are declining. White women in the age group encompassed by this study attended less prestigious law schools than white men with comparable LSAT scores and college records, but that difference has disappeared. ${ }^{44}$ Elite law schools appear to be hiring more female and minority scholars. ${ }^{45}$ As trends like these continue, the biographies of white women, women of color, and men of color will more closely match those of white men. With that shift, the analyses reported here suggest that sex and race differences in citation rates will also diminish.

Mentors concerned about the progress of female and minority scholars, moreover, can counsel faculty aspirants on ways to build their scholarly influence. Early productivity, for example, is associated with higher citation counts. Mentors should encourage women and minority students to publish early, a practice that will enhance both their hiring prospects and their longterm scholarly influence. ${ }^{46}$ Faculties should also insure that men and women

${ }^{44}$ See Merritt \& Reskin, supra note 2, at 285 \& n.258; Ronald M. Pipkin, Entropy and Skewness in the Allocation of Students to Law Schools, 59 Wash. U. L. Q. 901 (1981); Ronald M. Pipkin, The Effects of Social Origin in the Allocation of Law Students, 34 J. Legal Educ. 385 (1984).

${ }^{45}$ By 1993-94, women and minorities made up almost one-quarter of the tenured/tenuretrack faculties at 32 top law schools. Eisenberg \& Wells, supra note 3, at 402 (these faculties included 75.2 percent white men, 16.3 percent white women, 5.6 percent men of color, and 2.9 percent women of color).

${ }^{46}$ On the other hand, women's disproportionate responsibility for childbearing and child care may impede productivity for some women during the early stages of their careers. Law faculties may need to accommodate a variety of publication patterns among men and 
have the same opportunity to teach constitutional law, a subject associated with high citation rates and accompanying influence. ${ }^{47}$

The final factor suggesting optimism about the future of female and minority scholars is the extraordinary success of four women of color in this cohort. An African American woman earned the highest citation total in this study; two other African American women joined her among the top five; and a fourth African American woman ranked tenth. A white woman also ranked among the 10 most-cited scholars to give that top 10 a remarkable demographic profile: half female and 40 percent African American. These achievements resoundingly defeat any notion that women or people of color cannot scale the pinnacle of scholarly influence..$^{48}$

Despite these bright prospects, I close by raising two caveats. First, some skeptics have questioned the type of citations garnered by white women, women of color, and men of color. Are citations to these scholars concentrated in narrow fields? Are these professors cited primarily by other scholars of the same race or sex? Do citations to female and minority faculty indicate serious attention to their work, or are these more cursory references? Even if white women, women of color, and men of color have achieved scholarly influence, in other words, how is that influence felt? ${ }^{49}$

women. Similar accommodation appears necessary for faculty candidates who have devoted part of their early careers to private practice. On average, professors with private practice experience published significantly fewer articles in top-20 journals before joining the tenure track (.173) than did professors who worked exclusively for government agencies, public interest groups, or academic institutions $(.371, p=.000)$. As equation (5) suggests, that gap was associated with fewer citations for faculty with private practice experience. Once I controlled for prehiring productivity (equation (6)), the difference disappeared-as it did for both white women and women of color. The pressures of private practice, like those of child care, may reduce early publications but need not impair long-term productivity.

${ }^{47}$ Among the 1,086 professors who began teaching 1981-91, 18.0 percent of the men and 11.1 percent of the women listed at least one constitutional law course in the 1990-91 Directory of Law Teachers $(p=.003)$. By 1996-97, more members of both groups taught a constitutional law course, but the sex difference was still significant: 23.2 percent of men and 14.2 percent of women listed at least one course in that field $(p=.002)$. Eisenberg and Wells found a smaller, nonsignificant sex difference among all faculty teaching at 32 selected law schools. In that group, 20.8 percent of men and 16.2 percent of women taught constitutional law. Eisenberg \& Wells, supra note 3 , at 413 n.43. Although this difference was nonsignificant, it is noteworthy that it follows the same trend.

${ }^{48}$ See also Eisenberg \& Wells, supra note 3 (finding few sex and race differences in citation rates among professors at 32 top law schools, especially after controlling for years in teaching); Lindgren \& Seltzer, supra note 24 , at 804 (finding that men of color were well represented among the 25 most prolific professors in the top journals, while women were well represented among the top 125).

${ }^{49}$ In part, questions like these reflect persistent doubts about the abilities of female and minority scholars. Frances Olsen, for example, has suggested that the success of women and minorities in citation counts may ultimately "delegitimate citation tallies as a source of prestige." Frances Olsen, Affirmative Action: Necessary but Not Sufficient, 71 Chi.-Kent L. Rev. 937, 937 (1996). As outsiders succeed on traditional academic measures, our stereotypes 
Full answers to these questions go beyond the scope of this paper. The sheer number of citations accumulated by the most successful female and minority scholars, however, refutes the notion of limited influence. The median citation count among all professors in my population was 52; the three most cited African American women earned 745, 766, and 995 citations apiece. It strains credulity to believe that a scholar could rise so far above the median while attracting perfunctory citations or citations from a limited group of authors. As R. H. Coase wrote with respect to citations to one of his own articles, "[I]t is most improbable" that an author who "has been cited [more than 900 times] has not had a considerable influence on legal scholarship." 50

Examination of the 50 most recent sources citing the top three African American women in this population, moreover, suggests that these citations are neither cursory nor limited to scholars of a particular sex or race. For each of these scholars, more than half of the citing sources contained multiple references, which suggests serious attention to the cited work. The proportion of sources including multiple references was virtually identical to that for the two white men who also ranked among the five most cited scholars. ${ }^{51}$ These two white men and three women of color were equally likely to be cited by both law professors and others (including students, attorneys, judges, foreign law professors, and professors from disciplines other than law). ${ }^{52}$ And the three women of color obtained their citations

about the outsiders may lead us to question the worth of the measures rather than to accept the success of the outsiders. I do not, therefore, want to confer too much legitimacy on this set of questions. It is useful, however, to ask whether white women, white men, men of color, and women of color are cited in the same ways or whether patterns of scholarly influence differ in some systematic way among them. I offer the preliminary thoughts in text as a way of beginning that investigation.

${ }^{50}$ R. H. Coase, The Problem of Social Cost: The Citations, 71 Chi.-Kent L. Rev. 809, 810 (1996). Coase was referring to his 1960 article, The Problem of Social Cost, 3 J. Law \& Econ. 1 (1960), which had been cited 940 times in legal periodicals by May 1995. Although Coase referred to a particular article, an analogous sentiment applies to an author cited almost 1,000 times in the first decade of her tenure-track career.

${ }^{51}$ For the comparisons discussed in this paragraph, I examined the 50 most recent sources citing each of the top five professors in my population. For this particular variation, I counted the number of references in each article-rather than simply counting each source as a single citation (the basic method adopted above). My tallies somewhat underestimate multiple references because I counted only references to the author's full or last name, not "id." references, but they provide a rough guide to the depth of reliance in each citing source. For the three African American women, 52 percent, 52 percent, and 64 percent of the 50 most recent sources contained multiple references. Similarly, for the two white men, 50 percent and 66 percent of the citing sources contained multiple references.

52 On average, 74 percent of the sources citing the three African American women were authored by law professors, while 26 percent were authored by others. The white men averaged 73 percent of citing sources authored by law professors and 27 percent authored by others. 
from a more racially and sexually balanced group of law professors than did the two white men. ${ }^{53}$ These findings are merely suggestive of further citation studies that could be done, but they cast serious doubt on any arguments that citations to women of color (or white women and men of color) signify less scholarly influence than citations to white men.

A final, more substantial concern about the future of female and minority scholars lies in the disproportionate rate at which those scholars may leave the academy. The analyses reported here focus on professors who held tenure-track positions for 8-12 years. Women and minority faculty, however, were somewhat more likely than white men to leave the legal academy before that milestone. About one-fifth of white men ( 22.3 percent) who began tenure-track law teaching between 1986 and 1991 had left the tenure track by the fall of 1998 . More than a quarter of white women (26.5 percent) and minority men ( 28.6 percent) had left the tenure track, while almost one-third of minority women (32.9 percent) had done so. These differences did not achieve statistical significance, ${ }^{54}$ but their direction is troubling. Even though white women, women of color, and men of color become influential scholars when they remain in the academy, these professors may be more likely than white men to leave law faculties.

I repeated the regression analyses described above for the entire population that began teaching between 1986 and 1991, while controlling for departure from the tenure track. Leaving the tenure track, not surprisingly, showed a strong and significant association with lower citation rates in all

${ }^{53}$ I could identify race and sex reliably only for citing authors who were law professors, so these analyses are limited to that group. The three women of color averaged 10.7 citations from white male law professors, 7.7 citations from male law professors of color, and 7.7 citations from female law professors of color. On average, therefore, they obtained 21 percent of their citations from professors sharing their own sex and race-and 29 percent of their citations from scholars sharing neither their sex nor race. The two white men averaged 22 citations from white male law professors, 12 citations from white female law professors, 2.5 citations from male law professors of color, and 0 citations from female law professors of color. The white men thus obtained 60 percent of their citations from professors of their sex and race-and no citations (among these 50 most recent citing sources for each professor) from professors who shared neither their sex nor race. Without knowing the demographic composition of all law professors publishing during the last year, it is difficult to evaluate these figures. White men probably still author the majority of law articles published each year. If so, the citing sources for the white men I sampled may accurately reflect the demographics of publishing, while those for the African American women may be skewed. However, with women and minorities composing about one-third of today's law faculties (see note 1 supra) and that percentage continuing to rise, it is equally plausible that both white men and women of color (as well as white women and men of color) generate a disproportionate number of their citations from scholars of the same sex and race. One could raise as much concern about the tendency of white men to generate citations from a limited group of scholars as about any such tendency among white women, women of color, or men of color.

${ }^{54}$ In a one-way analysis of variance, $F(3,1082)=2.04, p=.106$. 
equations. Otherwise, the outcomes for these regressions differed little from the results reported above; in particular, the sex and race effects were comparable. New variables interacting departure from the tenure track with the three dummy variables for sex and race failed to attain significance, except that the interaction term for women of color who left the tenure track was negative and significant in equation (7). Women of color who departed teaching, in other words, saw their citations decline even more than did white women, white men, or men of color who had similar levels of productivity and also left the tenure track.

Future work will explore further possible sex and race differences among law professors who leave teaching. For present purposes it is sufficient to sound a warning that, although women and minorities who remain in teaching have been quite successful in building scholarly influence, these scholars appear somewhat more likely than white men to leave the tenure track early in their careers. And, at least for women of color who leave teaching, that departure may foretell an even greater loss of scholarly influence than occurs for white men, white women, and men of color.

\section{Conclusion}

In just 20 years, the sex and race composition of the legal academy has changed dramatically. The analyses reported in this article suggest that the white women, women of color, and men of color who joined law faculties during the late $1980 \mathrm{~s}$, and who remain on the tenure track today, have established themselves as influential legal scholars. Average citation counts for these scholars lag somewhat behind those for white men, but the differences are small and largely attributable to gaps in socioeconomic background, educational preparation, number of prehiring publications, and fields of specialization. As differences in the latter variables diminish, so should the remaining discrepancies in citation counts. The outstanding performance of several African American women, finally, confirms the ability of female and minority scholars to achieve the highest levels of scholarly influence-even as newcomers to the academy. 